\title{
La Administración Pública
} frente al ciudadano en Nicaragua. Un Goliat frente a un David. (La deficiente regulación jurídica, estructuración orgánica y humana de la justicia constitucional y administrativa como una causa de esa disparidad)

Juan Bautista Arríen Somarriba*

* Profesor de tiempo completo. Facultad de Ciencias Jurídicas, UCA, Apdo. 69, Managua, Nicaragua. E-mail: ArrienSo@yahoo.com.mx ArrienSo@hotmail.com

Recibido: septiembre de 2006 / Aceptado: octubre de 2006

EN ESTE ARTÍCULO REALIZAMOS UN ANÁLISIS DE LOS RECURSOS administrativos y judiciales existentes en nuestro país para solucionar los conflictos jurídicos que suceden entre los distintos órganos de la Administración Pública y los ciudadanos. Exponemos una serie de deficiencias jurídicas que posee tanto el procedimiento del recurso de amparo como el contencioso - administrativo, comenzando por los recursos administrativos necesarios para acceder a ambos. Presentamos también diversos comentarios sobre la estructuración orgánica y humana tanto de la Jurisdicción constitucional como de la administrativa, planteando una reforma general de las mismas, así como una propuesta de reforma constitucional, de la ley de carrera judicial, de la ley de organización, competencias y procedimientos del Poder Ejecutivo y de la normativa contenciosa - administrativa.

Palabras clave: Nicaragua-administración pública/procedimiento administrativo / recursos administrativos / recurso contencioso administrativo / recurso de amparo 


\section{Introducción}

La presente investigación me ha llevado a conocer la realidad práctica de la justicia administrativa nicaragüense ${ }^{1}$, es decir la forma en que se resuelven los conflictos jurídicos entre la Administración Pública y los ciudadanos. El primer sujeto se nos presenta como una entidad orgánica de grandes dimensiones, con gran capacidad económica y privilegios; mientras que el segundo carece de esas características.

Ambos sujetos mantienen en momentos determinados una estrecha relación jurídica que se tramita mediante distintos procedimientos administrativos ${ }^{2}$, es decir el ciudadano le solicita algo a la administración y ésta, por medio de una serie de trámites, le responde de forma negativa o positiva o no responde ${ }^{3}$; pensemos, por ejemplo, en la concesión que es necesaria para poder distribuir un servicio público (caso de Unión Fenosa), o en la licencia para poner una radio, o en el permiso que se necesita para un hotel turístico, entre otros. Todos esos ejemplos poseen una actuación administrativa bajo terminologías distintas (concesión, licencia, permiso, autorización) que constituyen la resolución al procedimiento administrativo, es decir la respuesta a la solicitud del ciudadano.

En esa relación jurídica puede, como es natural, surgir un desacuerdo entre las partes, haber pretensiones distintas, es decir originarse un conflicto jurídico - administrativo, un pleito, consistente, casi siempre en la negativa que da la Administración a la solicitud hecha por el ciudadano.

Esas relaciones y conflictos están regulados por normas jurídicas de carácter constitucional y ordinario, de naturaleza administrativa. Existen dos posibles caminos para solucionarlos: el recurso de amparo, normado por la ley de amparo ${ }^{4}$, que tiene rango constitucional, y el recurso contencioso - administrativo, regulado por la normativa con el mismo nombre, de carácter ordinario. Ambos recursos se recepcionan por las salas civiles de cada tribunal de apelaciones según el domicilio del ciudadano, éstas admiten o no el recurso, emiten o no la medida cautelar de suspensión del acto, y remiten el recurso a la sala constitucional de la Corte Suprema de Justicia en el primer caso, y a la Contencioso - Administrativo en el segundo caso, para obtener mediante un procedimiento, escrito en el primer caso y oral en el segundo, una sentencia de fondo, resolviendo el conflicto con carácter de cosa juzgada, es decir de forma irrecurrible.

Antes de acceder a estos recursos, ambas normas, obligan al ciudadano a agotar la vía administrativa, es decir, a interponer al menos dos recursos administrativos; el primero de revisión ante el funcionario que emitió el acto administrativo, que le causa daños o perjuicios, y el segundo, el de apelación ante el superior jerárquico, con el fin de obtener una resolución. Esta vía administrativa permite una revisión de la actuación recurrida, sin necesidad de acceder a un juicio o proceso judicial, largo, tedioso y costoso.

El eje de la investigación radica en analizar jurídicamente tanto la regulación normativa de estos recursos como la estructura orgánica - humana judicial, que se encarga de resolver los conflictos entre los sujetos señalados. Dicho análisis nos llevará a conclusiones y recomendaciones que posiblemente signifiquen propuestas concretas de reorganización 
de dicha estructura y de reforma a la normativa señalada. En otras palabras, podríamos estar frente a una propuesta de reforma constitucional, con el fin de plantear una reforma orgánica dentro del Poder Judicial nicaragüense, especialmente en la Corte Suprema de Justicia. Así mismo, podríamos llegar a una reforma de la ley de amparo, de la normativa contenciosa - administrativa, de la ley de organización, competencias y procedimientos del Poder Ejecutivo y hasta de la carrera judicial, con el fin de encontrar un medio más eficiente para la tutela de los derechos, intereses y garantías de los nicaragüenses.

\section{Planteamiento del problema}

Una vez expuestos brevemente los procedimientos judiciales para el control de la actuación administrativa, el lector se preguntará, qué problema tienen, en qué perjudican al ciudadano, por qué y cómo violentan sus derechos e intereses.

La primera problemática que se nos presenta radica en la desigualdad entre las partes en conflicto, la administración con una serie de privilegios, mientras que el ciudadano no los posee. Pero además, el procedimiento administrativo que origina todo tipo de actuación administrativa no está regulado en una normativa general, por lo que cada órgano administrativo se ha encargado de regular vía reglamentaria casi todos los trámites que el ciudadano debe de realizar frente a ellos; por lo tanto, se ha creado una lista impresionante de procedimientos ${ }^{5}$ y regulaciones que el ciudadano no domina y hasta desconoce.

La segunda problemática radica en la vía administrativa que es necesario agotar para acceder a los recursos judiciales. El problema se encuentra en la poca utilidad que poseen los recursos administrativos que integran la misma, debido a que ambos se interponen ante el mismo órgano administrativo que emitió la actuación recurrida, por lo que éste se convierte en juez y parte, siendo muy difícil conseguir una resolución a favor del ciudadano, por el excesivo subjetivismo de los funcionarios públicos respecto a sus resoluciones, sinónimo de respaldo de su prestigio profesional y su poder público.

Por otro lado, los recursos judiciales tienen grandes similitudes en su tramitación, ambos se interponen ante el mismo órgano judicial, y son resueltos por la Corte Suprema de Justicia, en la Sala Constitucional el amparo y en la contencioso - administrativo el recurso del mismo nombre. Hay una evidente centralización orgánica y territorial de la justicia constitucional y administrativa, lo que provoca que ciudadanos que habitan departamentos o municipios que no poseen un Tribunal de apelaciones tengan que recorrer grandes distancias para hacerlo, pero además al final desembocan en Managua. Por esta razón se les trata de forma desigual que a los ciudadanos que habitan lugares que cuentan con dicho órgano judicial, y podríamos estar frente a la ruptura del principio de igualdad ante la ley (arto. 27 de la constitución). Esta excesiva centralización ha llevado a un estancamiento de la Corte Suprema de Justicia (principalmente la sala constitucional) porque conocen y resuelven todo tipo de materia, hasta las de más mínima importancia, lo que ha ocasionado una grave retardación de justicia constitucional - administrativa.

Además, ambos recursos sólo estipulan en su tramitación la suspensión del acto administrativo, pero muchas veces la administración no actúa, y lo que se pretende es que 
actúe porque la ley así lo señala y sin embargo no lo hace. Pensemos en el caso en el que tiene que pagarte por tus servicios profesionales y no lo hace, o te tiene que devolver dinero por un cobro indebido y no lo hace, o tiene que prestar un servicio al cual se tiene derecho y no lo presta. En otras palabras en todas estas actuaciones no vale de nada suspender acto administrativo, porque no lo hay. Lo que se necesita es motivar la creación de la actuación mientras se resuelve el conflicto. Esta problemática es de procedimiento y perjudica al ciudadano al restar efectividad a la sentencia final.

Finalmente, hay que señalar que la integración humana de nuestro más alto tribunal, en el cual se resuelven ambos recursos judiciales, procede de nombramientos directos hechos por los diputados de la Asamblea Nacional. Inclusive el Presidente de la República puede proponer candidatos para ocupar magistraturas en la Corte Suprema de Justicia, es decir, puede proponer a sus juzgadores. Como podemos apreciar, de una u otra forma los partidos políticos tienen la posibilidad constitucional y legal de incidir en estos nombramientos, pero el problema no termina ahí, porque como los magistrados de la corte son los que nombran a los magistrados de los Tribunales de apelaciones, la cadena política se alarga. Podríamos estar frente a una grave politización de la justicia constitucional y administrativa, lo que causa indefensión, desigualdad, retardación de justicia y desbarata todos los cimientos del Estado de derecho que queremos construir. Inclusive se atenta en contra de la inversión económica extranjera y nacional, porque un inversionista quiere reglas del juego claras para invertir y, por su puesto, un poder judicial ágil, efectivo, despolitizado, en el cual pueda, apegado a la ley, resolver sus conflictos con la administración.

OBJETIVO GENERAL: Analizar las distintas problemáticas planteadas sobre el desarrollo de la justicia constitucional y administrativa nicaragüense, así como plantear algunas propuestas de resolución a las mismas.

OBJETIVOS ESPECÍFICOS:

1. Brindar una perspectiva general de las principales características de la relación jurídica administrativa entre la Administración Pública y el ciudadano.

2. Describir el trámite de los recursos administrativos en Nicaragua, como una antesala obligatoria para poder acceder a la vía judicial para resolver los conflictos administrativos entre los ciudadanos y la Administración Pública.

3. Analizar el procedimiento judicial de los recursos de amparo y del contencioso administrativo, con la finalidad de incidir en una posible reforma de los mismos, mediante una propuesta orgánica y humana para lograr la descentralización y la despolitización de la justicia constitucional y administrativa en Nicaragua.

HIPOTESIS: La centralización orgánica de la justicia constitucional y administrativa nicaragüense, así como su politización, son factores que atentan contra la eficiencia necesaria para la defensa de los derechos, garantías e intereses de la ciudadanía.

METODOLOGÍA:

Esta investigación tiene un carácter descriptivo y explicativo. Pretende no sólo exponer 
la situación de desventaja en la cual nos encontramos los ciudadanos frente a los órganos estatales, sino también incidir en los medios jurídicos de defensa que poseemos, sobre todo el recurso de amparo y el contencioso - administrativo, por medio de una serie de propuestas de reforma a los mismos.

Para obtener conclusiones, resultados prácticos y para proponer algunas recomendaciones nos apoyamos en la utilización de la entrevista ${ }^{6}$ como medio para obtener información. Así mismo, realizamos una recopilación doctrinaria y jurisprudencial en instituciones públicas tanto de Nicaragua como de España. Finalmente, hemos tratado de imprimir a la investigación la experiencia práctica que en el ejercicio de la profesión hemos ido acumulando, así como los aportes que hemos hecho al dictamen de la normativa del contencioso - administrativo que está en discusión en la Comisión de Justicia de la Asamblea Nacional.

\section{Capítulo I: La Administración Pública y el ciudadano. Dos sujetos en una relación impar. Un Goliat frente a un David.}

\section{La Administración Pública nicaragüense}

Se nos presenta como una entidad conformada por un sinnúmero de órganos administrativos, todos agrupados en un orden jerárquico predeterminado por la ley, en tres grandes unidades básicas.

A la primera se le denomina Administración Pública central7; está conformada por los doce ministerios, y por los entes descentralizados ${ }^{8}$ y desconcentrados ${ }^{9}$. A la segunda se le denomina administración municipal ${ }^{10}$, es decir, las alcaldías, las cuales están regidas desde el punto de vista ejecutivo por el Alcalde, y desde el punto de vista normativo por un Consejo municipal, integrado por concejales. A la tercera unidad organizativa de la administración pertenece la administración regional ${ }^{11}$, tan olvidada y marginada durante los gobiernos, pero tan recordada durante los años electorales. En las regiones autónomas existe también un órgano normativo, el Consejo regional, una autoridad ejecutiva como es el Coordinador regional. Así mismo, cuenta con autoridades municipales y comunales.

Cada una de estas unidades administrativas esta regulada por su propia normativa jurídica ordinaria y tiene su base constitucional en la división política administrativa del país que realiza nuestra carta magna ${ }^{12}$, ya que la misma carece de un título o capítulo dedicado exclusivamente a exponer el régimen jurídico general de la Administración Pública, que difiera de la normativa que rige al Gobierno ${ }^{13}$, como sucede por ejemplo en la constitución española ${ }^{14}$.

La Administración Pública en general se caracteriza por ser una entidad de carácter público, cuya finalidad es preservar el interés general. Cuenta con una serie de privilegios legales como, por ejemplo, la inembargabilidad de sus bienes, la auto tutela. Es decir que el ciudadano debe recurrir primero ante sus órganos (agotar la vía administrativa) y luego ante el control judicial en contra de sus actos, los cuales nacen y se presumen válidos (ejecutividad), pero además puede ejecutarlos por si misma. Posee la capacidad recaudadora de tributos, su presupuesto, la fuerza pública (policía y ejército) entre otros. 


\section{El ciudadano}

A diferencia de los órganos administrativos el ciudadano se nos presenta como una persona natural o jurídica, sin los privilegios que caracterizan a aquéllos. Sus bienes son embargables, soporta una carga tributaria que a su vez es utilizada por la propia administración, inclusive para su defensa (Procuraduría General de Justicia); sus actos no son ni ejecutivos ni ejecutables sin la intervención de un judicial, pero además tienen que soportar el peregrinaje judicial, que la justicia constitucional y administrativa les obliga a agotar, hasta llegar a una sentencia firme que resuelva sus conflictos con la administración.

Ese peregrinaje genera una seria carga económica que, si bien puede ser solventada por el beneficio de pobreza o la defensoría pública, nos damos cuenta que en esta última, por ejemplo, se pasan graves crisis económicas: no hay suficiente personal para enfrentar la carga de casos en estas materias, y finalmente hay muy poca capacitación en los defensores públicos en las mismas ${ }^{15}$. Pero, además el ciudadano siempre llegará a chocar frente a la muralla de los privilegios de la Administración.

\section{Capítulo II: La justicia constitucional - administrativa en Nicaragua.}

Denominaremos justicia constitucional - administrativa ${ }^{16}$ a la posibilidad de obtener una sentencia judicial que permita un control de la actuación ${ }^{17}$ de la Administración Pública, una vez que se ha agotado la vía administrativa ${ }^{18}$ interna, mediante la utilización de los recursos administrativos ${ }^{19}$ (revisión, apelación). Este control judicial se realiza por medio del recurso de amparo o por medio del recurso contencioso - administrativo.

1. La vía administrativa (los recursos administrativos, verdaderos privilegios de la Administración Pública, juez y parte en los mismos)

Decíamos, que antes de acceder al órgano judicial, es necesario agotar esta vía de control interno, por medio de la interposición de los recursos administrativos ${ }^{20}$ que, según la ley $290^{21}$ (artos. $39-46$ ), son el recurso de revisión y el de apelación. Sin olvidar que una ley particular puede regular otros ${ }^{22}$, los cuales se convierten así en una carga procesal, en un pre requisito obligatorio ${ }^{23}$ y preclusivo. Es decir, no se puede acceder a aquel órgano (judicial) sin agotar esta vía ${ }^{24}$.

El primero de esos recursos se da a favor de aquellos ciudadanos cuyos derechos se consideren perjudicados por los actos emanados de los Ministerios y entes a que se refiere la ley 290. Deberá interponerse en el término de quince días hábiles a partir del día siguiente de la notificación del acto. El escrito de interposición deberá expresar el nombre y domicilio del recurrente, acto contra el cuál se recurre, motivos de la impugnación y lugar para notificaciones. Es competente para conocer y resolver el órgano responsable del acto. La interposición del recurso no suspende la ejecución del acto, pero la autoridad que conoce del recurso podrá acordarla de oficio o a petición de parte, cuando la misma pudiera causar perjuicios irreparables al recurrente. Se resolverá en un término de veinte días, a partir de la interposición del mismo. 
El segundo recurso se interpondrá ante el mismo órgano que dictó el acto, en un término de seis días después de notificado. Éste remitirá el recurso junto con su informe al superior jerárquico en un término de diez días. Se resolverá en un término de treinta días, a partir de su interposición, agotándose así la vía administrativa y legitimando al agraviado a hacer uso del recurso de amparo ${ }^{25}$ y de lo contencioso - administrativo.

\subsection{Comentarios al procedimiento de ambos recursos:}

- Ambos recursos tienen la finalidad de permitir al órgano administrativo autor del acto o a su superior, proceder al replanteamiento de su resolución; pero en nuestro país esto ocurre con muy poca frecuencia.

- El órgano administrativo se convierte, se quiera o no, en juez y parte en el mismo conflicto. Esto ocasiona un sobre apasionamiento subjetivo del funcionario público que esta resolviendo el recurso, el cual ve a su acto inicial como una carta de presentación de su labor, de su prestigio profesional, olvidando que, como cualquier ser humano, pudo haber cometido un error que perjudicara tanto al ciudadano como a la administración. También el órgano inferior teme cambiar su acto inicial por posibles represalias del superior, debido a que llegan a sus puestos por nombramientos directos, muchas veces de carácter político. Y es que la ley de servicio civil y carrera administrativa ${ }^{26}$ que establece el sistema de concurso y oposición para obtener un cargo público a través de capacidades profesionales y técnicas, todavía esta en pañales en cuanto a su ejecución real.

- Como posible solución de los hechos mencionados, se podría seguir la descentralización orgánica que ha creado el Código Tributario ${ }^{27}$ (artos. 203 - 213) cuando delega en un Tribunal Tributario Administrativo, ajeno a la Dirección General de Ingresos, la resolución del recurso de apelación en esa materia. Esta medida orgánica podría generar una cierta independencia en la resolución de los recursos administrativos.

- Por otro lado, no existe en la ley 290 un plazo para la emisión de la medida cautelar de suspensión del acto. Tampoco determina qué pasa si no hay resolución a la solicitud de las mismas. En el derecho comparado español se ha optado por aplicar el silencio positivo, es decir, sin no hay resolución en el término de ley, se entiende suspendido el acto ${ }^{28}$. Esta es una medida ejemplar que debería seguir nuestra futura ley de procedimiento administrativo. No estamos de acuerdo con la suspensión automática del acto, o sea con la mera interposición del recurso, porque se podría perjudicar a un tercero, y todos recurrirían sólo para obtener la suspensión.

- En nuestra opinión, el recurso de revisión tiene menos sentido y eficacia que el de apelación, porque se interpone y es resuelto por la misma autoridad que emitió el acto, por lo cual se duda de obtener una resolución a favor. Motivo por el cual hemos propuesto que el mismo sea opcional y se pueda recurrir de apelación de forma directa, buscando mayor imparcialidad e independencia. En la Comisión de Justicia de la Asamblea Nacional se ha optado por proponer dicho carácter a ambos recursos, ante lo cual no estamos de acuerdo porque se perdería la oportunidad de evitar un proceso judicial 
para ambas partes.

- Consideramos que el término de los seis días para interponer el recurso de apelación es extremadamente corto, casi fugaz, y los que ejercemos el litigo desde la práctica lo sabemos, porque es necesario preparar el recurso. Proponemos ampliarlo al menos a diez o quince días como un término standar para recurrir. En el sistema español se habla de un mes y hasta de tres meses ${ }^{29}$.

- Resulta inútil desde nuestro punto de vista interponer este último recurso ante el mismo funcionario que resolvió el primero. Esto coloca a las partes en desventaja, pues se le otorga al órgano inferior la posibilidad de conocer los fundamentos jurídicos y las pretensiones del ciudadano, para preparar su defensa, antes de que el recurso llegue al verdadero juzgador (el superior). Estamos frente a otro privilegio administrativo sin razón jurídica alguna. ¿Qué pasaría si no remite el recurso al superior? Pero además, ¿qué es el informe? ¿cuál es su finalidad? ¿No es acaso una repetición del expediente administrativo que se ha ido tramitando? Por lo tanto, el informe muchas veces no es más que una simple repetición de información contenida en el mismo.

Hemos propuesto a la Comisión de Justicia en la elaboración del dictamen del proyecto de ley de procedimiento administrativo, que el recurso de apelación sea interpuesto directamente ante el superior jerárquico, que se le notifique al inferior y que se le dé un plazo para que remita su contestación, poniendo así a ambas partes en igualdad.

- Como el lector podrá apreciar, la normativa que regula el último recurso no establece la posibilidad de pedir nuevamente medida cautelar de suspensión, lo cual desde la práctica nosotros siempre hacemos. Debería de legislarse en ese sentido, pero además se debería de apuntar a que la medida cautelar de suspensión pueda trascender de un recurso a otro y hasta a la vía judicial. De otra manera caeríamos en la inutilidad de pedirla hasta tres veces, ante tres funcionarios distintos, cuando el que emitió el acto ya consintió que se suspenda el mismo.

- Vemos que en nuestra legislación tampoco se permite al ciudadano optar o no por agotar esta vía o por sustituirla por algún medio alterno de resolución de conflictos, como ocurre en el sistema español ${ }^{30}$. Nos referimos a la utilización del arbitraje administrativo u otros medios de transacción.

- Se debería regular la funcionalidad de la figura de la prohibición de la reformatio in pejus $^{31}$. Es decir, que mediante la resolución del recurso administrativo no se pueda agravar la situación del recurrente.

- También se debería de regular la admisión del recurso si el ciudadano se ha equivocado en el nombre del mismo, o lo ha interpuesto ante un órgano administrativo que no debía.

- Se necesita una urgente reforma de la ley 290, o mejor aún, la pronta aprobación de una verdadera ley de procedimiento administrativo general, que establezca las bases tanto 
del procedimiento administrativo ordinario como el de recursos.

\section{El recurso de amparo (la espera del ciudadano por una sentencia que nunca llega, y cuando lo hace ya no tiene sentido)}

Este recurso ${ }^{32}$ sólo puede interponerse por parte agraviada ${ }^{33}$. Se entiende por tal, toda persona natural o jurídica a quien perjudique o esté en inminente peligro de ser perjudicada por toda disposición, acto o resolución, acción u omisión de cualquier funcionario, autoridad ${ }^{34}$ o agente de los mismos, que viole o trate de violar los derechos y garantías constitucionales (artos. 188 de la constitución y 3 de la ley de amparo $^{35}$ ).

Se interpondrá, en el término de treinta días de notificada la actuación, ante la Sala civil del Tribunal de Apelaciones respectivo, la que conocerá de las primeras actuaciones hasta la suspensión del acto inclusive ${ }^{36}$, correspondiéndole a la Corte Suprema de Justicia (Sala de lo Constitucional) el conocimiento ulterior hasta la resolución definitiva. El escrito del recurso $^{37}$ es en papel común con copias suficientes para las autoridades señaladas como responsables y para la Procuraduría General de Justicia.

El Tribunal de Apelaciones concederá al recurrente un plazo de cinco días para que llene las omisiones de forma. Si el recurrente dejase pasar este plazo, se tendrá por no interpuesto. El Tribunal, dentro del término de tres días de interpuesto el recurso, de oficio o a solicitud de parte, deberá decretar la suspensión del acto contra el cual se reclama, o denegarla en su caso. Al decretarse la suspensión, el Tribunal fijará la situación en que habrán de quedar las cosas y se tomarán las medidas pertinentes para conservar la materia objeto del amparo, hasta la terminación del respectivo procedimiento.

El Tribunal pedirá a los señalados como responsables, envíen informe a la Corte Suprema de Justicia. Deberá rendirse dentro del término de diez días, contados desde la fecha en que reciban el correspondiente oficio. Con él se remitirán las diligencias de todo lo actuado.

Recibidos los autos por la Sala Constitucional de la Corte Suprema de Justicia, con o sin el informe ${ }^{38}$, se dará al amparo el curso que corresponda. La sentencia definitiva se emitirá dentro de los cuarenta y cinco días posteriores a la recepción de las diligencias y sólo se referirá a las personas que hubieren interpuesto el recurso, limitándose si procediese a ampararlo, indicando los fundamentos legales en que se apoya para declarar la legalidad o ilegalidad del acto reclamado. Dictada la sentencia ${ }^{39}$, la sala la comunicará dentro del término de tres días hábiles a las autoridades o funcionarios responsables para su cumplimiento; igual cosa hará con las demás partes.

Si dentro de las veinticuatro horas siguientes a la notificación las autoridades o funcionarios responsables no dieren cumplimiento a la sentencia, en el caso de que la naturaleza del acto lo permita, la Corte requerirá al superior inmediato para que obligue a éstos a cumplir sin demora la sentencia.

Cuando la misma no se obedeciese a pesar de los requerimientos, la Corte pondrá los hechos en conocimiento de la Presidencia de la República para que proceda a ordenar su cumplimiento, 
e informará a la Asamblea Nacional, sin perjuicio de poner el caso en conocimiento de la Procuraduría General de Justicia, para que derive las acciones correspondientes.

\subsection{Comentarios sobre el recurso de amparo:}

- Actualmente este recurso se interpone no sólo para defender los derechos subjetivos constitucionales, sino también lo expuesto en normativa ordinaria, lo que es propio del contencioso - administrativo ${ }^{40}$. Por lo que podría originarse una confusión.

- No existe la posibilidad de que el tribunal de apelaciones emita otra medida cautelar que no sea la suspensión del acto, pero ¿qué hacemos cuando no hay acto, sino inactividad? Consideramos que debería de reformarse la ley de amparo para permitir todo tipo de medida cautelar, incluyendo las positivas, cuando el caso así lo amerite y sea legal, pero sobre todo posible. Ante la ausencia de este tipo de medida cautelar los tribunales de apelaciones se ven imposibilitados también de ejecutar la figura del silencio administrativo positivo ${ }^{41}$.

- Ante la centralización en una sola sala de la corte (la constitucional) para resolver estos recursos se ha originado una grave retardación de justicia que los mismos magistrados reconocen $^{42}$, lo que provoca graves perjuicios al ciudadano.

- Muchas personas ${ }^{43}$ han expresado la idea de reformar la constitución con el fin de crear un Tribunal Constitucional dentro o fuera del Poder Judicial, para conocer y resolver de forma exclusiva este recurso ${ }^{44}$. Ese tribunal podría estar integrado por magistrados seleccionados por medio de concurso público u oposiciones, con el fin de lograr una especialización humana y jurídica de la materia. Esta propuesta también podría significar una reforma a la ley de carrera judicial ${ }^{45}$ para que estos magistrados sean sometidos a los mecanismos de selección mencionados y que no queden excluidos como sucede en la actualidad. Lógicamente, una reforma como la que se propone también trastocaría la ley de amparo y la ley orgánica del poder judicial ${ }^{46}$ y su reglamento ${ }^{47}$.

- Podría pensarse también en otras posibles reformas a la ley de amparo promoviendo, por ejemplo, la oralidad tal y como sucede en la materia penal y contencioso administrativa. La realidad del caso es que una reforma al sistema constitucional de amparo nicaragüense es necesaria y urgente, debido a que el sistema actual enfrenta graves problemas y podría estar muy cerca del colapso, si no es que ya ha pasado.

\section{El contencioso - administrativo (un recurso que funciona de forma parcial)}

El contencioso - administrativo es un recurso que puede utilizar el ciudadano una vez agotada la vía administrativa. Este recurso abre un proceso judicial compuesto por un procedimiento dividido en etapas, con actos de trámite en cada una y que tiene la característica general de la oralidad.

La Jurisdicción de lo contencioso - administrativo, es decir los órganos que tramitan y resuelven dicho recurso conocen con potestad exclusiva de las pretensiones que se deduzcan 
en relación con los actos, resoluciones, disposiciones generales, omisiones y simples vías de hecho, así como en contra de los actos que tengan que ver con la competencia, actuaciones y procedimientos de la Administración Pública. Se interpondrá ante el Tribunal de Apelaciones, Sala para lo Civil de los mismos, la que determinará la tramitación de las primeras actuaciones hasta la suspensión del acto inclusive, correspondiéndole a la Sala de lo Contencioso Administrativo de la Corte Suprema de Justicia el conocimiento ulterior hasta la resolución definitiva.

Las etapas del procedimiento son las siguientes:

- INICIACION: Es necesaria la interposición de un recurso, no hay posibilidad de inicio de oficio. Dicho recurso debe llenar casi los mismos requisitos que el del amparo. Las partes deben de concurrir a una mediación. Si no logran acuerdo, el tribunal debe, en un plazo de tres días, emitir la media cautelar que es siempre la suspensión del acto, aún y cuando este recurso puede interponerse en contra de la inactividad administrativa, donde no existe acto, por esta razón durante la discusión del dictamen de la reforma de esta normativa propusimos que el tribunal inferior pudiese emitir la medida cautelar que considerase ajustada al caso y que fuera legal.

Posteriormente, se emplazara a la Administración Pública, la cual deberá de remitir el expediente administrativo para que el recurrente lo tenga a la vista seis días antes del juicio oral. El órgano administrativo deberá rendir un informe (especie de contestación de la demanda) alegando sus pretensiones. Siempre hemos considerado que esta figura del informe ${ }^{48}$ no coincide con el carácter procesal del recurso contencioso administrativo y se debería de hablar en su lugar de una contestación con las excepciones correspondientes.

- DESARROLLO: Durante el juicio oral el Presidente de la Sala respectiva del Tribunal declarará abierto el debate y concederá la palabra al actor o demandante para que haga una sucinta exposición de sus pretensiones y de los fundamentos fácticos y jurídicos de ellas. A continuación, dará la palabra a la parte demandada para que, también sucintamente, exprese lo que estimare pertinente en relación con la demanda. De inmediato se procederá a la incorporación de la prueba documental que hubiere sido admitida.

Posteriormente se oirá a los testigos y peritos, empezando por los ofrecidos por el demandante. El actor, el demandado y los miembros de la Sala respectiva del Tribunal, en ese orden, podrán formular preguntas a los testigos y peritos, pero se abstendrán de adelantar conclusiones. Cuando corresponda el turno de oír a los testigos y peritos de descargo, precederá en el interrogatorio el demandado al actor y a los miembros del Tribunal. Las partes finalizaran el juicio oral con sus alegatos conclusivos los cuales también son orales.

- SENTENCIA: La Sala de lo contencioso - administrativo de la Corte emitirá sentencia estimando o no el recurso, lo que puede llevar a la desaparición del acto e inclusive a indemnizaciones por daños y perjuicios causados al ciudadano. 
- RECURSOS JUDICIALES: Contra la sentencia caben el recurso de aclaración, reposición y reforma, los cuales se interponen ante la misma Sala de lo contencioso de la Corte.

- EJECUCIÓN: La ejecución de la sentencia queda en manos de dicha sala, la cual emitirá todas las medidas pertinentes para materializar los efectos de la misma.

\subsection{Comentarios sobre el contencioso - administrativo}

- La normativa ${ }^{49}$ que regula este recurso ha sido declarada parcialmente inconstitucional, debido a que el pleno de la Corte consideró que la creación de Salas de lo Contencioso - Administrativo en los Tribunales de Apelaciones atentaba contra la exclusividad que la sala de esta materia de la Corte posee según el arto. 164 inc. 10 y 11 de la constitución y, por lo tanto, es el único órgano competente para resolverlo; mientras que la ley (350) le daba competencia a esas salas inferiores. En la actualidad han quedando sólo dos materias activas en litigio (reglamentos y conflictos entre órganos administrativos). Por eso sosteníamos que éste es un recurso con funcionalidad parcial. Ante esta sentencia la Corte envió a la Asamblea Nacional una iniciativa de reforma, que está siendo dictaminada por la Comisión de Justicia, que en concreto centraliza toda la materia contenciosa - administrativa en cuanto a la resolución del fondo en dicha sala de la Corte, originándose la misma centralización que sucede en el amparo.

- El alejamiento de la justicia administrativa de los administrados que habitan Departamentos o Regiones que no poseen un Tribunal de Apelaciones, justifica la urgente necesidad de impulsar un mecanismo que descentralice y acerque esta justicia al administrado. La Administración Pública no sólo actúa en Managua o en los Departamentos que cuentan con un Tribunal de Apelaciones, sino también, lógicamente, en aquellos en los que no existen estos órganos. Podría nuevamente pensarse en la posibilidad de que los Juzgados recepcionen los recursos o demandas ${ }^{50}$ y los remitan al Tribunal de Apelaciones respectivo, o se podría ser más radical y apuntarnos a una reforma constitucional con el fin de procurar una estructuración orgánica de esta jurisdicción basada en una serie de posibilidades. Por ejemplo, las salas de la materia que se querían constituir en los Tribunales de apelaciones o verdaderos Tribunales de lo Contencioso - Administrativo, teniendo a la sala de la Corte como última instancia, entre otras.

- En otra oportunidad hemos hecho algunos señalamientos ${ }^{51}$ ante la Comisión de Justicia sobre el dictamen, entre los que sobresalen: No establece absolutamente nada respecto a la posibilidad de poder ampliar el recurso por determinadas causales

- Se ha confundido la figura de la contestación del recurso (demanda) con la emisión de un informe, contra el cual no se puede recurrir. Consideramos que carece de sentido y razón, tanto jurídica como lógica, la emisión de un informe, cuando lo que va a informarse ya esta contenido en casi toda su extensión en el expediente administrativo. Sería conveniente regresar a la noción de la contestación de la demanda con su respectiva notificación al recurrente, para que éste pueda ampliar su recurso si así fuera el caso. 
- Las medidas cautelares están centradas sólo en la suspensión del acto administrativo, es decir, medidas negativas ${ }^{52}$, pero no en la emisión de medidas positivas, como el mandato de la emisión de una actuación concreta ante la inactividad administrativa. La aprobación de una cláusula general de medidas cautelares, que permita la emisión de la que corresponda según el caso concreto es absolutamente necesario.

- El dictamen no establecía la posibilidad procesal de emitirse sentencia sin necesidad de celebrarse alegatos orales, pruebas y conclusivos -algo plenamente posible en el Derecho Procesal Administrativo Español ${ }^{53}-$, máxime cuando el órgano judicial ya tiene en el recurso, en el llamado informe y sobre todo en el expediente administrativo todos los hechos y fundamentos jurídicos para emitir una sentencia.

- Es necesaria una fuerte reforma en materia de ejecución de sentencias en este aspecto, entre las que sobresalen: Establecer en el dictamen que cuando la Administración fuere condenada al pago de cantidad líquida, el órgano encargado de su cumplimiento acordará el pago con cargo al crédito correspondiente de su presupuesto que tendrá siempre la consideración de ampliable. Que cualquiera de las partes pueda solicitar que la cantidad a satisfacer se compense con créditos que la Administración ostente contra el recurrente. La posible inscripción en los registros correspondientes donde los efectos del acto administrativo tuvieron acceso. Regular la posibilidad de la ejecución subsidiaria de las sentencias con cargo de los costos en la Administración vencida. Finalmente, regular multas o sanciones pecuniarias para los funcionarios o agentes de los mismos que se nieguen a ejecutar las sentencias, como un medio coercitivo para lograr la ejecución de las mismas

Este es el momento de incidir en la aprobación de una moderna y eficaz normativa contencioso - administrativa. Estos comentarios podrían tener alguna utilidad en pro de no caer en las mismas deficiencias que hemos señalado respecto al amparo.

\section{Conclusiones}

1. Nuestra carta magna carece de una normativa que diferencie los términos Gobierno y Administración Pública. Por lo tanto, la organización administrativa del Estado nace de la división política administrativa que establece la misma constitución. Ambos términos se utilizan sin discriminación alguna.

2. La Administración Pública se nos presenta cobijada por una serie de privilegios que la sitúan en una posición de ventaja respecto al ciudadano.

3. Para acceder a la jurisdicción constitucional o administrativa, es necesario agotar la vía administrativa, es decir, interponer los recursos administrativos correspondientes, primero ante la autoridad que emitió la actuación administrativa en cuestión, y luego el de apelación ante su superior jerárquico, con el fin de obtener una resolución administrativa contra la cual proceder a la vía judicial. Estos recursos son un privilegio más de la administración, que sólo han visto disminuidos sus efectos pro administración gracias a la vigencia del silencio administrativo positivo. Es decir que, ante la ausencia 
de resolución, nace un acto presunto que favorece las pretensiones del ciudadano. El problema es que no existe una normativa jurídica para ejecutar o materializar dicho silencio.

Fijémonos cómo los recursos administrativos carecen de eficiencia, debido en parte a las siguientes causas: El subjetivismo imperante en los funcionarios administrativos que los resuelven, ya que resolver en contra de sí mismos resulta un poco desprestigiante, pero además los funcionarios obedecen a un nombramiento directo, muchas veces de carácter político, hecho por el superior, a quien no pueden contrariar cuando se les impone una forma de resolver los recursos en cuestión. Y es que, como sosteníamos, ambos funcionarios, tanto el superior como el inferior, no proceden de un sistema de carrera administrativa, es decir no son seleccionados por medio de concursos u oposiciones, por lo que no son inamovibles, y hasta podrían no ser los ciudadanos más apropiados, mejor preparados para ejercer el cargo público. Esta situación resta eficiencia administrativa, desmotiva al ciudadano, crea feudos políticos, pero sobre todo le resta el verdadero sentido que deberían de tener los recursos administrativos, como lo es otorgarle la posibilidad a la administración de revisar la actuación administrativa sin necesidad de llegar a un juicio o proceso.

4. No existe en Nicaragua una normativa de procedimiento administrativo que regule los principios generales para el trámite de los recursos administrativos en todas las materias. Tampoco poseemos una completa regulación jurídica de la vía judicial para controlar la actuación e inactividad de la administración. Es decir, poseemos una ley de amparo, pero la normativa contencioso - administrativo está parcialmente vigente. Lo anterior nos deja frente a una Administración con un amplio margen de actuación discrecional, que la puede llevar a caer en la arbitrariedad, generando un ambiente de desconfianza en la ciudadanía, en el empresario privado, en el inversionista.

5. Ambas normativas se caracterizan por un control centralizado de dicha actuación administrativa, ya que en ambos casos son salas de la Corte Suprema de Justicia, las que resuelven el fondo de los conflictos jurídico - administrativos. Esto permite deducir que hay una posible trasgresión del principio de igualdad ante la ley ${ }^{54}$ a la hora de recurrir contra la Administración Pública, en dependencia del lugar que se habita. Un ciudadano de cualquier municipio del país tendrá que venir a fuerza a litigar contra la administración a la capital, generándole un incremento en los gastos legales, de transporte, entre otros, lo que podría ocasionar una apatía popular a la hora de recurrir. Mientras que el de Managua no sufrirá esos gastos. El sistema orgánico de justicia constitucional y administrativa podría ser inconstitucional, al causar un factor de movilidad para ciertos ciudadanos y para otros no.

6. Esa centralización orgánica tiene también otro grave efecto, como lo es la retardación de justicia, debido a que todos los conflictos administrativos desembocan en un sólo órgano judicial, que se ve desbordado.

7. Los funcionarios judiciales que integran la Sala constitucional y contencioso administrativo de la Corte Suprema de Justicia, no son seleccionados bajo los principios 
y mecanismos de carrera judicial, es decir, mediante concursos u oposiciones, sino que proceden de nombramientos directos hechos por los diputados de la Asamblea Nacional ${ }^{55}$.

\section{Recomendaciones}

1. Es necesaria una reforma constitucional en los siguientes puntos, para conseguir varias finalidades:

- Reformar el arto. 164 incisos 3, 10 y 11 de la Carta Magna, con el fin de descentralizar la jurisdicción de amparo y la contencioso - administrativa, permitiendo crear órganos judiciales inferiores, por ejemplo Tribunales Contencioso - Administrativos o hasta juzgados de la materia. Así mismo, plantear la posibilidad de crear un Tribunal Constitucional.

- Reformar el artículo 138 incisos 7 y 11 con el fin de quitarle a la Asamblea Nacional la posibilidad de nombrar a Magistrados en la Corte Suprema de Justicia, así como la atribución que tiene el Presidente de la República (arto. 150 inc. 4 de la Constitución) de proponer a los mismos. Así podríamos poner en marcha un sistema de carrera judicial por medio de concursos y oposiciones que incluyan a dichos funcionarios. En otras palabras, con esta reforma constitucional reformaríamos directamente la ley de carrera judicial, para que esos sistemas de selección que posee cubran a los magistrados de la Corte Suprema de Justicia.

2. Aprobar a lo inmediato una Ley de procedimiento administrativo general, que cubra a toda la Administración Pública, con el fin de establecer un procedimiento común (con período probatorio, informes de otros órganos administrativos, audiencia oral, entre otros actos) para tramitar las solicitudes de los ciudadanos.

3. La ley anterior debería de contener una reforma al sistema de los recursos administrativos en la que se podría tomar en cuenta las siguientes propuestas:

- Otorgarle el carácter opcional al recurso de revisión, es decir, si el ciudadano quiere utilizarlo que lo haga sino que acceda directamente al de apelación.

- Regular la posibilidad de interponer directamente el recurso de apelación ante el superior jerárquico del funcionario que emitió la actuación en cuestión.

- Ampliar los términos para recurrir a la vía administrativa.

- Aplicar el silencio administrativo positivo cuando no haya pronunciamiento sobre la emisión de la medida cautelar de suspensión del acto administrativo recurrido, para preservar así la eficacia de la sentencia final.

- Regular por ley un procedimiento para ejecutar el acto presunto obtenido mediante silencio administrativo positivo. Consideramos que se le debería de otorgar la 
competencia al órgano administrativo que conoce y resuelve los recursos, tanto al inferior como al superior, para que pueda mandar a ejecutar el acto presunto, con la simple presentación de la copia del recibido de la solicitud o del recurso, para computar el plazo. Pero además se le debería de dar la misma competencia a los Tribunales de apelaciones, al interponerse recurso de amparo o contencioso administrativo cuando se recurra por la falta de ejecución del silencio. Finalmente, dicha competencia se debería de extender a la Sala de lo Contencioso-Administrativo de la Corte Suprema de Justicia.

4. Recomendamos la pronta aprobación de la reforma a la ley de lo contencioso administrativo, con el fin de contar con un medio de control judicial más amplio de la actuación e inactividad de la Administración Pública, para lo cual hemos hecho una serie de propuestas de reforma al procedimiento de trámite de dicho recurso.

5. Por último, pero no menos importante, recomendamos que en las universidades se apueste por reformar los planes de estudio con la visión de preparar a funcionarios públicos y judiciales, duchos en las materias propias del Derecho Administrativo, que al fin y al cabo regulan toda actuación de la Administración Pública y los órganos judiciales que controlan la misma. Podría dividirse dicha clase, así como la de Derecho Constitucional, en tres materias (parte general, especial y procesal), como lo está haciendo la Universidad Centroamericana.

\section{Notas}

1 Por esta razón esta investigación ha sido enriquecida con vasta jurisprudencia no sólo nacional (de la Sala constitucional y de lo Contencioso - Administrativo de la Corte Suprema de Justicia de Nicaragua), sino también del derecho comparado español.

2 Es el cauce formal de la serie de actos en que se debe concretar la actuación administrativa sujeta al Derecho Administrativo para la consecución de un fin (arto. 2, inc. 13 ley 350, reguladora de la Jurisdicción de lo Contencioso - Administrativo, La Gaceta No. 140 y 141 del 25 y 26 de Julio del 2000). Ver GONZÁLEZ (2001).

3 Si la administración no responde se origina el silencio administrativo, el cual tiene dos sentidos: el primero negativo, es decir una ficción que permite acceder al siguiente recurso, el segundo positivo 0 a favor del ciudadano, originándose así un acto presunto que le favorece, pero que materialmente no existe. Ver: Sentencia de la Sala de lo Contencioso - Administrativo de la Corte Suprema de Justicia \# 7 del año 2004 y la \# 2 del año 2005. Se puede consultar: GUILLÉN (1997).

4 Ley 49, La Gaceta No. 241 de 20 de diciembre de 1988.

5 Ver algunos ejemplos en la web: www.ucresep.gob.ni

6 Hemos recogido a lo largo de casi cinco años, la opinión de diversos magistrados de la Sala de lo Contencioso - Administrativo, del Tribunal de Apelaciones, Jueces de Distrito y Local tanto civiles como penales, que hoy son magistrados, diputados de la Comisión de Justicia de la Asamblea Nacional, catedráticos y especialistas en la materia, entre otras personas.

7 Se le denomina central, porque está organizada desde un punto de vista centralizado, con una dirección central, el Presidente de la República, que dirige la labor de los ministros y éstos a su vez dirigen la labor de toda una estructura orgánica, en cada uno de sus ministerios, dividida en niveles. En cada nivel hay una serie de órganos administrativos y dentro de estos a su vez hay otra escala jerárquica de funcionarios, hasta llegar al nivel inferior. Está regulada por la ley 290, de organización, competencias y procedimientos del Poder Ejecutivo, La Gaceta No. 102 del 3 junio 1998.

8 Según el arto. 4 de la ley 290 , es una forma de organización administrativa en la cual se confiere, a través de una ley, a un órgano autonomía técnica y administrativa para ejercer determinada competencia administrativa. Se le otorga patrimonio propio y personalidad jurídica, existiendo control o tutela del Presidente de la República o del Ministerio al que estén vinculados. El Director del ente es nombrado por el Presidente de la República o por la autoridad establecida de acuerdo a su ley creadora. 
9 Es una forma de organización administrativa en la cual un órgano centralizado confiere autonomía técnica a un órgano de su dependencia para que ejerza una competencia limitada a cierta materia o territorio. El ente gubernamental que tiene administración desconcentrada no tiene patrimonio propio ni personalidad jurídica, su status legal y presupuesto devienen del Ministerio al que están vinculados jerárquicamente. Ver ESCORCIA (2002: 339-340).

10 Está regulada por la ley 40 y sus reformas, de municipios, La Gaceta no. 162, del 26 de agosto de 1997.

11 Regulada por el Estatuto de Autonomía, La Gaceta no. 238, del 30 de octubre de 1987.

12 Titulo X de la Constitución (artos. 175 al 181).

13 Recordemos que el Gobierno y la Administración Pública están dirigidas por el Presidente de la República. El primero es una entidad que emite directrices políticas, mientras que el segundo se encarga de ejecutarlas. Ver ESCORCIA (2002: 33 - 74).

14 La Constitución Española dedica todo un título, el IV, al Gobierno y la Administración. Recomendamos la lectura de dos textos (entre los muchos que hay) (Nieto, 1991: 2185-2253; Fernández, 2002). Una regulación normativa sobre la Administración Pública de Nicaragua en la Constitución Política es fundamental, necesaria y de carácter urgente.

15 Recomendamos la obra de Aráuz y Moreno (2001).

16 Ver GARRIDO (2004).

17 Según el inciso 1 del arto. 2 de la ley no. 350, acto administrativo, es la declaración o manifestación de voluntad, juicio 0 conocimiento expresada en forma verbal o escrita o por cualquier otro medio que, con carácter general o particular, emitieren los órganos de la Administración Pública y que produjere o pudiere producir efectos jurídicos.

18 Ramón P. Vázquez (1999: 379-381), señala que se llama vía administrativa o gubernativa, a la línea jerárquica existente entre los órganos administrativos de un mismo ente público. Constituye un procedimiento administrativo que contiene recursos administrativos o reclamaciones previas a la vía jurisdiccional que tratan de abrir una vía de revisión de la actuación de la Administración Pública. Esta técnica administrativa tiene una doble función, la primera evitar que la Administración Pública resulte enjuiciada sorpresivamente ante los Tribunales Contencioso - Administrativos, otorgándole un plazo en ocasiones demasiado largo, de reflexión y respiro; la segunda, y más importante, servir de medio de garantía y defensa de los derechos e intereses de los administrados que podría evitar un proceso judicial largo y tedioso. El problema es que la primera función se está convirtiendo en un privilegio y protección para la Administración Pública y la segunda en una carga administrativa para los administrados debido a la retardación y hasta la ausencia de resolución y tramitación de los mismos por el ente público(Régimen jurídico de las administraciones públicas y procedimiento administrativo común, 1999, p. 379381). Las Sentencias del Tribunal Constitucional español (SSTC 61 / 1986 de 21 de enero y la 204 / 1987 de 21 de diciembre) han afirmado que: "La vía administrativa del recurso es admisible cuando responda a razonables finalidades de protección de bienes e intereses constitucionalmente protegidos sin que en ningún caso pueda representar un obstáculo carente de racionabilidad y proporcionalidad respecto de los fines que lícitamente puede perseguir el legislador" Véase PEMÁN (s.f.: 158).

19 GONZALEZ (2004: 2514) los define como actos de impugnación de un acto administrativo anterior ante un órgano de éste carácter, que dan lugar a un procedimiento de revisión. Los recursos administrativos constituyen vías de revisión a instancia siempre de interesados, sujetas a plazos determinados.

20 El sistema de los recursos, tanto en vía administrativa como en la jurisdiccional, es el principal medio imaginado para remediar, dentro de lo humano, posibles errores, desviaciones o arbitrariedades de las autoridades y órganos encargados de tomar decisiones, en sus respectivas parcelas de poder. Sentencia del Tribunal Supremo Español (STS) Sección 5ta, de la Sala de lo Contencioso - Administrativo de 11 de diciembre de 1991. Según la STS de 13 de julio de 1983: Constituyen una garantía para el administrado, que permiten una auto revisión a la Administración de sus propios actos para que ésta pueda acceder a las pretensiones de aquél y evitar los perjuicios que un proceso jurisdiccional comporta.

21 Ley no. 290, publicada en La Gaceta No. 102 del 3 junio 1998

22 Por ejemplo, el Código Tributario regula el de reposición, revisión y apelación. Ver artos. 93 - 101 ley no. 562, La Gaceta no. 227 del 23 de noviembre del 2005.

23 González Pérez sostiene que la configuración del recurso administrativo como presupuesto procesal carece de sentido. Bien está que se admita la posibilidad de acudir al recurso administrativo cuando exista alguna esperanza de que, a través de él, las Administraciones Públicas abandonen su terquedad tradicional, pero no obliguen en todo caso a la interposición. De aquí la unanimidad de que la doctrina española venía defendiendo que el recurso administrativo tuviera carácter potestativo. Ver los artículos de Tornos (1993), González (1993) y Campo (1993).

24 Esto según el arto. 45 ley 290, 46 de la ley 350, y 27 de la ley de amparo.

25 Nuestra Corte Suprema de Justicia ha dicho que si no existe recurso administrativo que agotar, puede recurrirse de amparo directamente S. de las 11: 30 del 6 de junio de 1995, BJ, p. 35, entre muchas otras.

26 Ley no. 476, La Gaceta no. 235 del 11 de Diciembre del 2003.

27 Ley no. 562, La Gaceta no. 227 del 23 de Noviembre del 2005. 
28 Artos. 72 y 11 de la Ley 30/1992, de 26 noviembre 1992. Régimen Jurídico de las Administraciones Públicas y del Procedimiento Administrativo Común. BOE, 27 noviembre 1992, núm. 285/1992 (www.boe.es)

29 Artos. 115 y 117 de la ley de procedimiento administrativo español.

30 Huergo (2000).

31 La Sentencia del Tribunal Supremo español (STS) del 31 de diciembre de 1990 recuerda el principio de que el reclamante es el único que puede obtener mediante su recurso o bien la permanencia de la misma situación inicial o una mejora en ella, pero nunca una agravación. La STS de 14 de diciembre de 1990 afirma rotundamente que la reformatio in pejus esta proscrita en todo caso de recurso, sea administrativo o jurisdiccional. La Administración incurriría en incongruencia si realiza una reformatio in pejus.

32 No procede el recurso de amparo: 1) Contra las resoluciones de los funcionarios de su competencia. 2) Cuando la infracción producida por el acto reclamado sea irreparable, material o jurídicamente. 3) Contra los actos que hubieren sido consentidos por el agraviado de modo expreso o tácito. Se presumen consentidos aquellos actos por los cuales no se hubiere recurrido de amparo dentro del término legal, sin perjuicio de la suspensión del término de conformidad al derecho común.

33 La Corte Suprema de Justicia de Nicaragua ha sostenido que es improcedente el amparo interpuesto por persona diferente del agraviado S. de las 11 am del 3 de febrero de 1988, BJ p. 32.

34 Como vemos el amparo sólo procede contra actos de autoridad y no de particulares. Sentencias de la Corte Suprema de las $11 \mathrm{am}$, del 3 de marzo de 1916 BJ, p. 1916, de las 10: 30 am del 26 de marzo de 1996.

35 Ley no. 49, La Gaceta no. 241 de 20 de diciembre de 1988. Esta ley es el instrumento legal mediante el cual se ejerce el control de ordenamiento jurídico y de las actuaciones de los funcionarios públicos para mantener y restablecer el imperio de la constitución. S de las 10: 45 del 7 de agosto de 1995, BJ, p. 105.

36 La suspensión provisional del acto recurrido no admite recurso. S de las 10: $30 \mathrm{am}$, del 2 de febrero de 1979, BJ, p. 459.

37 Deberá contener: 1) Nombres, apellidos y generales del agraviado y de la persona que lo promueva en su nombre. 2) Nombre, y apellidos y cargos del funcionario, autoridades o agentes de los mismos contra quien se interpone el Recurso. 3) Disposición, acto, resolución, acción u omisión contra los cuales se reclama, incluyendo si la ley, decreto ley, decreto o reglamento, que a juicio del recurrente fuere inconstitucional. 4) Las disposiciones constitucionales que el reclamante estime violadas. 5) El Recurso podrá interponerse personalmente o por apoderado especialmente facultado para ello. 6) El haber agotado los recursos ordinarios establecidos por la ley, o no haberse dictado resolución en la última instancia dentro del término que la ley respectiva señala. 7) Señalamiento de casa conocida en la ciudad sede del Tribunal para subsiguientes notificaciones. Ver S. de las 10: 45 del 12 de junio de 1995 BJ, p. 47

38 La falta de informe establece la presunción de ser cierto el acto reclamado (arto. 39 ley de amparo).

39 Contra la cual no cabe recurso alguno.

40 Ver sentencia no. 1 del año 2003, de la Sala de lo Contencioso - Administrativo de la Corte Suprema de Justicia, Considerando II, donde esta Sala expresa claramente la diferencia entre el recurso de amparo y el contencioso - administrativo y cuando recurrir a uno u otro recurso: "Esta Sala es del criterio que el demandante debió de impugnar dichas normas mediante la presentación del recurso de amparo, ya que éstas, según lo expresado por el apoderado de los demandantes, se consideran violatorias a la Constitución Política, pues éste es el medio que la Constitución y la Ley de Amparo establecen para impugnar este tipo de acto o resoluciones, asimismo como lo señalamos en el considerando anterior, el arto. 17 inco. 2 de la Ley 350, excluye del conocimiento de la Jurisdicción de lo Contencioso Administrativo lo referente a las violaciones o intento de violación de los derechos y garantías consagrados en la Constitución Política por corresponder a la Jurisdicción Constitucional." Ver también la sentencia No. 3 del año 2005 y la no. 1 del año 2006

41 Sobre esta figura ver las sentencias no. 7 del año 2004 y no. 2 del año 2005 de la Sala de lo Contencioso - Administrativo de la Corte Suprema de Justicia.

42 EL NUEVO DIARIO: "CSJ intenta parar abusos en la tramitación del amparo", 24 de agosto del 2006.

43 NOGUERA (1992).

44 Siguiendo así el modelo español (www.tribunalconstitucional.es)

45 Ley 501, La Gaceta no. 9, 10 y 11 del 13, 14 y 17 de enero de 2005.

46 Ley no. 260, La Gaceta No. 137 del 23 Julio 1998.

47 Decreto 63 - 99, La Gaceta No. 104 del 2 de Junio de 1999.

48 Ver los comentarios que hemos hecho sobre esta figura en el recurso de amparo.

49 Ley no. 350, Reguladora de la Jurisdicción de lo Contencioso - Administrativo, publicada en La Gaceta no. 140 y 141 del 25 y 26 de Julio del 2000.

50 Ver el arto. 25 de la ley 350.

51 Ver: Apuntes sobre el contencioso - administrativo en Nicaragua. (Folleto que utilizamos en dicha clase en la UCA) 2005.

52 Ver los mismos comentarios respecto al recurso de amparo. 
53 Arto. 62, Ley 29 / 1998, reguladora de la Jurisdicción Contencioso-Administrativa. BOE 14 julio de 1998, núm. 167 [Pág. 23516 ] 54 Expuesto en el art. 27 de la Constitución: "Todas las personas son iguales ante la ley tienen derecho a igual protección...." 55 Ver arto. 138 inc. 7 de la Constitución.

\section{Referencias bibliográficas}

-ARÁUZ, M.y MORENO, M. (2001).Imagen de la Justicia, independencia y asociacionismo en el sector judicial nicaragüense. Managua: UCA Publicaciones.

-ARRÍEN, J. (2002). "El Procedimiento Administrativo y el Proceso Contencioso Administrativo en Nicaragua", Revista de la Facultad de Derecho de la Universidad Centroamericana, No. 2, Managua.

-(2005). Los recursos administrativos en el sistema español y nicaragüense. Folleto para la clase de Derecho Contencioso - Administrativo. Biblioteca UCA.

-CAMPO (1993). "Otro ejemplo del carácter de gravamen de la vía gubernativa para los administrados" en La Protección Jurídica del administrado. Estudios en homenaje al Profesor Jesús González Pérez. Madrid: Cívitas, pág. 1018.

-COSCULLUELA, L. (2004). Manual de Derecho Administrativo. Tomo I. España: Editorial Aranzadi. -ESCORCIA, J. (2002). Derecho Administrativo. León: Editorial Universitaria.

-FERNÁNDEZ, T. (2002). De la arbitrariedad de la Administración. Madrid: Editorial Cívitas, cuarta edición.

-FORNOS, I. (1998 - 2002). Manual de Derecho Constitucional y Derecho Procesal Constitucional. Managua: Editorial Hispamer.

-GARCÍA, E. (2004). Curso de Derecho Administrativo. Tomo II. Madrid: Editorial Thomson - Cívitas, 9na edición.

-GARRIDO (2004). La justicia administrativa, en Tratado de Derecho Administrativo III. -GONZÁLEZ, J. (2001). Manual de Derecho procesal Administrativo. Madrid: Editorial Cívitas, 3ra edición.

-GONZÁLEZ, J. (2003). Comentarios a la Ley de la Jurisdicción Contencioso Administrativo. Tomo I. Madrid: Editorial Cívitas, 4ta edición.

-GONZÁLEZ, P. (1993). "Los efectos de la extemporaneidad del recurso en vía administrativa y la seguridad jurídica" en La Protección Jurídica del administrado. Estudios en homenaje al Profesor Jesús González Pérez. Madrid: Cívitas, pág. 797.

-GUILLÉN, M. (1997). El silencio administrativo. El control judicial de la inactividad administrativa.

-HUERGO,A.(2000).LaresoluciónextrajudicialdeconflictosenelDerechoAdministrativo. La transacción, el arbitraje y la reforma de los recursos administrativos. Bolonia: Publicación del Real Colegio de España.

-NIETO, A. (1991). La Administración sirve con objetividad los intereses generales, en Estudios sobre la Constitución Española, Homenaje al Profesor Eduardo García de Enterria, Tomo III. Madrid.

-NOGUERA, M. (1992). Necesidad de la creación del Tribunal Constitucional en Nicaragua. Tesis de Monografía. León: Universidad Nacional Autónoma de Nicaragua.

-PARADA, R. (2004). Derecho Administrativo. Parte general, Tomo I. Barcelona: Editorial Marcial Pons, decimoquinta edición.

-PEMÁN, J. (s.f.). "Vía administrativa previa y derecho a la tutela judicial", Revista de Administración Pública (RAP), 127.

-TORNOS, J. (1993). "Vía previa y garantía de los administrados" en La Protección Jurídica del administrado. Estudios en homenaje al Profesor Jesús González Pérez. Madrid: Cívitas, pág. 647. 